\title{
Os impactos da pandemia de Covid-19 para as mulheres imigrantes no Brasil: mobilidade e mercado de trabalho
}

\author{
Tania Mara Passarelli Tonhati (https://orcid.org/0000-0002-1841-977X), \\ Instituto de Ciências Sociais, Universidade de Brasília (UnB), \\ Brasília, Distrito Federal, Brasil'.
}

Marília de Macêdo (https://orcid.org/0000-0002-0793-3650), Observatório das Migrações Internacionais (OBMigra), Brasília, Distrito Federal, Brasil".

Resumo: O presente artigo tem como objetivo apresentar os impactos da pandemia de Covid-19 nos fluxos migratórios de mulheres imigrantes para e no Brasil. Para isso, analisamos de forma comparativa, o período de janeiro a setembro de 2019 e 2020, tendo como alicerce as informações contidas nas bases de dados da Polícia Federal, sobre a chegada das imigrantes pelos postos de fronteiras (STI) e o registro migratório (SisMigra). Ademais, analisamos a inserção e a movimentação das trabalhadoras imigrantes no mercado de trabalho formal no Brasil, a partir da base de dados harmonizada Relação Anual de Informações Sociais (Rais), Carteira de Trabalho e Previdência Social (CTPS) e Cadastro Geral de Empregados e Desempregados (Caged), do Ministério da Economia, para o mesmo período. Os dados revelaram que, até o presente momento, a pandemia de Covid-19, tem contribuído para manter e acirrar os eixos de desigualdades (gênero, classe, grupo-étnico-racial e origem), que impactam o acesso das mulheres imigrantes a recursos.

Palavras-Chaves: Pandemia de Covid-19. Mulheres imigrantes. Brasil.

\section{The impacts of the Covid-19 pandemic on immigrant women in Brazil: mobility and the labour market}

Abstract: This article presents the impacts of the Covid-19 pandemic on female migratory flows to Brazil. The methodological approach was a comparative study, considering the period from January to September 2019 and 2020, and based on the information contained in the Federal Police databases, on the arrival of immigrants through border checkpoint (STI) and the migratory registration (SisMigra). In addition, we analyzed the insertion of migrant women in the formal labour market in Brazil, using the harmonized databases of Annual Social Information List (Rais), Work and Social Security Card (CTPS) and General Register of Employees and Unemployed (Caged), from the Ministry of Economy, for the period previously mentioned. The study has revealed that, so far, the Covid-19 pandemic has contributed to maintain and intensify the axes of inequality (gender, class, ethnic-racial group and origin), which impact immigrant women's access to resources.

Keywords: Covid-19 pandemic. Immigrant women. Brazil.
Recebido: 31.12 .20

Aprovado: 07.06 .21
I. Tania Mara

Passarelli Tonhati é professora adjunta do Departamento de Sociologia do Instituto de Ciências Sociais da UnB. <tania.tonhati@unb. br>.

II. Marília de Macêdo é doutoranda pelo Programa de Pós-Graduação em Estudos Comparados sobre as Américas da UnB.

<marilia.macedo@ aluno.unb.br>). 
1. Sayad (2001) utiliza o conceito de "fato social total" de Marcel Maus (1986)

- "Ensaio sobre a dádiva" - para pensar as migrações contemporâneas.

\section{Introdução}

pandemia de Covid-19 afetou de forma inédita, sistêmica e multidimensional
quase todos os países do planeta, provocando impactos sem precedentes no
campo da saúde, da economia, das relações sociais, do turismo, da cultura, das fronteiras, dentre outros setores. As migrações internacionais, entendidas por Abdelmalek Sayad (2001) como "fato social total"1, constitui um dos fenômenos sociais que foi fortemente impactado pela pandemia e é tema sempre prioritário nas agendas dos governos nacionais, fóruns internacionais e nos discursos políticos, midiáticos e acadêmicos. As/os imigrantes, refugiadas/os e solicitantes de refúgio também foram afetadas/os pela pandemia de Covid-19. O vírus se globalizou, desconhecendo fronteiras e políticas restritivas de mobilidade, o que levou muitas/os migrantes a ficarem imobilizadas/os, postergarem seus projetos migratórios ou, ainda, ficarem vários dias e meses em trânsito. Essa situação tem sido particularmente dramática para as muIheres migrantes e refugiadas, que se tornam ainda mais vulneráveis, uma vez que estar em trânsito é um percurso incerto; há diversos relatos de atos de violência contra as mulheres nessa situação (Foley \& Piper, 2020; Andrade et. al. 2020).

No campo dos estudos migratórios, nos últimos anos, o fenômeno da feminização das migrações tem ganhado cada vez mais projeção. Esse termo ganhou grande relevância a partir da obra clássica de Stephen Castles, Hein De Haas e Mark J. Miller (1998), que indicava um aumento numérico substancial na migração feminina na contemporaneidade. Contudo, estudos feministas relatam que a dimensão da migração feminina já representava $47 \%$ do total de imigrantes internacionais em 1960, com incremento de apenas dois pontos percentuais até o ano 2000, chegando aos 49\% (Zlotnik, 2003). Desde o clássico trabalho de Mirjana Morokvasic (1984), diversos estudos constataram que as mulheres sempre integraram os processos migratórios e, muitas vezes, em números expressivos. No entanto, as suas vivências não eram pontos de debate, devido aos recortes de análise do campo migratório. Citamos aqui, por exemplo, a teoria push-pull, a neoclássica e a estrutural-histórica. Para mais exemplos ver Douglas Massey e equipe (1993), que tendiam a explicar as migrações relacionadas diretamente à variável da busca por trabalhos com melhores remunerações (ex: guest workers, imigrante econômico). Também, pela lógica idealizada da família nuclear, na qual o homem tende a ser o breadwinner (provedor), e a mulher migraria apenas visando à reunificação familiar. Esses vieses desconsideram o trabalho, remunerado ou não, das imigrantes, invisibilizando o protagonismo das mulheres nos processos migratórios.

Atualmente, de acordo com os dados das Nações Unidas (UN, 2019), as mulheres correspondem à, aproximadamente, metade dos 272 milhões $(47,9 \%)$ de pessoas 
que vivem e trabalham fora de seus países de origem e nascimento. O peso das mulheres imigrantes ultrapassa o dos homens, nos países desenvolvidos. Os dados da Nações Unidas (UN, 2019) demonstram, ademais, que regiões com uma longa tradição de imigração registraram as maiores parcelas de mulheres imigrantes. Em 2019, o percentual de mulheres entre todos os imigrantes internacionais foi maior na América do Norte $(51,8 \%)$ e na Europa (51,4\%). Diferentemente, em outras partes do globo, mulheres e homens compõem uma parcela quase equivalentes do total de imigrantes internacionais, conforme pode-se constatar na Oceania $(50,4 \%)$, na América Latina e no Caribe $(49,9 \%)$, na Ásia Central e Sul $(49,4 \%)$, e Leste e Sudeste $(49,3 \%)$.

Pesquisas embasadas por debates teóricos, metodológicos e empíricos dão suporte aos estudos concernente à migração feminina. Segundo Tânia Tonhati (2018), os avanços teóricos sobre as experiências das mulheres migrantes desenvolveram-se paralelamente ao crescimento e aos desdobramentos dos estudos feministas, e em consonância aos estudos sobre as migrações internacionais. Para a autora, as construções teóricas sobre esse tema, que correlacionaram as teorias feministas às migrações internacionais, proporcionaram que o protagonismo feminino com relação à migração saísse da invisibilidade. Entretanto, a literatura sobre o tema se concentra em construções teóricas, empíricas e metodológicas baseadas nas experiências das migrações Sul-Norte e são produzidas por pesquisadoras/es preocupadas/os com as migrações para e no Norte Global (ver, por exemplo, Boyd \& Grieco, 2003; Hondagneu-Sotelo, 2003; Padilla, 2007; Assis, 2007).

A prevalência desses estudos fez com que o paradigma predominante, para explicar as migrações femininas, as relacione, diretamente, à demanda e inserção laboral em atividades de reprodução dos papéis de gênero, dentro da perspectiva do cuidado: empregadas domésticas, babás, enfermeiras, cuidadoras de idosos (Ehrenreich \& Hochschild, 2002; Parreñas, 2001; 2002; 2009). Com relação ao contexto da migração de mulheres no Brasil, esse paradigma explicativo deve ser (re) analisado e (re)pensado, visto que os novos fluxos de imigrantes mulheres para o Brasil, a partir de 2010, apresentam suas peculiaridades. No Brasil, o número de mulheres imigrantes (incluindo solicitantes de refúgio e refugiadas) ainda é menor que o de homens. Todavia, nos últimos cinco anos, os dados demonstram que esse número vem crescendo. De acordo com Tânia Tonhati e Marília Macêdo (2020: 28), o Brasil, de 2010 a 2019, recebeu novos fluxos migratórios, os quais contrariam as tendências das migrações Sul-Norte e se caracterizam por serem mais masculinizados. Esse fato fez com que as experiências migratórias femininas ficassem, mais uma vez, invisibilizadas, posto que, em números absolutos, as mulheres imigrantes contabilizavam, em média, um terço das entradas no país, bem como eram menos 
presentes no mercado de trabalho. Em contrapartida, as autoras destacaram que, a partir da segunda metade da última década, até a chegada da pandemia de Covid-19, ocorreu um aumento no número de mulheres imigrantes chegando ao país e se inserindo no mercado de trabalho formal.

Dados analisados pelas autoras sobre a imigração feminina para o Brasil demonstraram que a, partir da segunda metade da década, prevaleceu a entrada das imigrantes sul-americanas e caribenhas no país, com destaque para as venezuelanas e para as haitianas, em sua maioria jovens e solteiras. Ademais, salientam que os dois principais nichos laborais das mulheres imigrantes no país são de ocupações voltadas para as áreas de serviços, particularmente na área de limpeza em espaços públicos ou empresas. Além disso, a pesquisa aponta desigualdade entre os rendimentos de homens e mulheres imigrantes e assinala as diferenças salariais entre as nacionalidades. Majoritariamente, as mulheres imigrantes possuem uma renda média de dois salários-mínimos.

A partir do estudo mencionado, outras questões relevantes surgiram, dentre elas: quais os impactos da pandemia de Covid-19 na mobilidade das mulheres imigrantes para o Brasil, incluindo as solicitantes de refúgio e refugiadas, e na sua inserção e permanência no mercado de trabalho formal?

O objetivo deste artigo é, portanto, refletir sobre esse questionamento, com vistas a traçar de que maneira e em qual extensão a pandemia de Covid-19 impactou na chegada e nos registros das mulheres imigrantes, assim como em sua inserção no mercado de trabalho formal.

Para atingirmos o objetivo proposto, analisamos, de forma comparativa, o período de janeiro a setembro de 2019 e 2020, tendo como alicerce as informações contidas nas bases de dados da Polícia Federal, sobre a chegada das imigrantes pelos postos de fronteiras (STI - Sistema de Tráfego Internacional) e o registro migratório (SisMigra - Sistema de Registro Nacional Migratório). Ademais, analisamos a inserção e a movimentação das trabalhadoras imigrantes, solicitantes de refúgio e refugiadas no mercado de trabalho formal no Brasil, a partir da base de dados harmonizada da Relação Anual de Informação Social (Rais), da Carteira de Trabalho e Previdência Social (CTPS), do Cadastro Geral de Empregados e Desempregados (Caged), do Ministério da Economia, para o mesmo período. Os dados foram tratados estatisticamente pelo Observatório das Migrações Internacionais (OBMigra). Esses mesmos dados foram trabalhados de forma agregada para os diferentes status migratórios - imigrantes, solicitantes de refúgio e refugiadas. Reconhecemos que essas diferentes categorias têm peculiaridades nas formas de deslocamento 
e inserção na sociedade de destino. No entanto, por uma questão metodológica e de apresentação do texto, os dados foram trabalhados de forma agregada. Consequentemente, neste artigo, o termo imigrante engloba também solicitantes de refúgio e refugiadas.

É importante ressaltar que os registros foram produzidos a partir do cruzamento das bases de dados do Rais, CTPS e Caged até 2019 e do e-Social, em 2020. Para mais detalhes sobre o tratamento estatístico dos dados, veja o capítulo "Notas metodológicas" do Relatório Anual do OBMigra (Quintino et al., 2020: 247-276).

\section{Análise dos fluxos migratórios de mulheres imigrantes durante a pandemia de Covid-19}

O avanço transfronteiriço do vírus da Covid-19 impôs a todas as pessoas uma imobilidade global e o distanciamento social. Para as mulheres imigrantes, o impacto tem sido imenso, interrompendo ou dificultando ainda mais os seus projetos migratórios. Segundo UN Women (2020), as mulheres se encontram em situação de maior vulnerabilidade com o fechamento das fronteiras e medidas restritivas de controle de viagens. Para Danielle Annoni (2020) e Paola Bergallo e equipe (2021), a pandemia de Covid-19 fez com que as mulheres se tornassem mais suscetíveis ao desemprego, à informalidade, à violência doméstica, muitas vezes convivendo em casa com os seus agressores, bem como se encerraram ainda mais no trabalho de cuidado não remunerado, e, quando em trânsito, se tornaram mais vulneráveis às ações e aos abusos dos atravessadores.

Para este artigo, procuramos apresentar os dados do STI e SisMigra, de janeiro a setembro de 2020, que nos permitem observar a movimentação (chegada e saída) e os registros junto a Polícia Federal de mulheres imigrantes. Assim, procuramos dimensionar, de forma numérica, como a mobilidade das imigrantes foi afetada pelas medidas restritivas implementadas, em consequência da pandemia de Covid-19. A análise foi feita por meio da comparação com o mesmo período de 2019.

As primeiras orientações da Agência Nacional de Vigilância Sanitária (Anvisa) foram editadas no mês de abril de 2020². A Portaria Interministerial 201, de 24 de abril, por exemplo, fechou as fronteiras aquaviárias; na sequência, a Portaria Interministerial, de 28 de abril, fechou as fronteiras aéreas; finalmente, a Portaria Interministerial 204, de 29 de abril, fechou as fronteiras terrestres. Esse cenário enrijeceu-se no mês de maio, com a edição de mais duas portarias: a do dia 22 de maio, Portaria 255, que estendia por mais 30 dias as restrições e, em 20 de junho, Portaria 319, acrescentava outro período de 15 dias às restrições.
2. As portarias não incluíram naturalizados, imigrantes residentes, não nacionais em missão oficial ou que fossem cônjuges, companheiros, filhos, pais ou curadores de brasileiro, ou cujo ingresso fosse autorizado especificamente pelo governo brasileiro em vista do interesse público ou por questões humanitárias. 
GRÁFICO 1

ENTRADA DE MULHERES IMIGRANTES NO TERRITÓRIO BRASILEIRO NOS PONTOS DE FRONTEIRA, POR MÊS, BRASIL, 2019-2020 (JAN. A SET.)

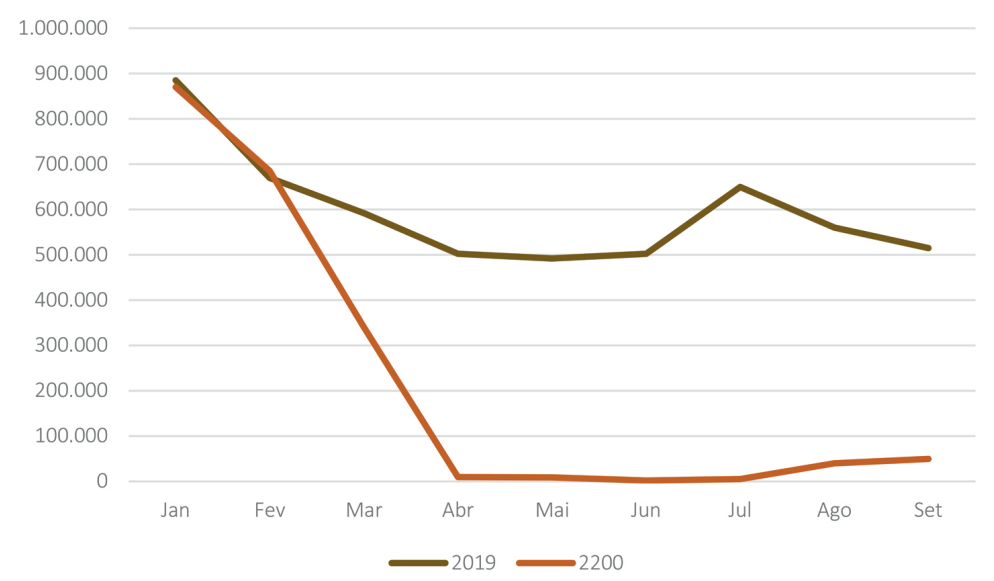

Fonte: Elaboração própria, a partir dos dados do OBMigra - Polícia Federal, Sistema Tráfego Internacional (STI), 2020.

No mês de abril de 2020 houve uma queda vertiginosa na movimentação de mulheres imigrantes nas fronteiras nacionais. Quando comparamos as movimentações de abril de 2019 com as de abril de 2020, os números revelam uma queda de $3.031 \%$ nas movimentações de mulheres na fronteira no país. Ao compararmos com os meses anteriores do ano de 2020, a queda é ainda maior. Em relação a janeiro, houve uma redução de -5.086\%; em comparação a fevereiro, a diminuição foi de $-4.036 \%$ e, em março, de $-2.133 \%$. Portanto, o mês de abril, definitivamente, marca o início do impacto da pandemia de Covid-19 na mobilidade migratória das mulheres nas fronteiras brasileiras.

A redução continua no mês de maio, mas mantém os números próximos ao mês de abril; por outro lado, nos meses de junho e julho, as movimentações retratam queda expressiva. Os meses de agosto e setembro de 2020 apresentam uma alta nas movimentações das fronteiras, contudo esse crescimento ainda está bem abaixo das movimentações do ano de 2019. Em relação a julho e agosto, houve um crescimento de $424 \%$, e setembro de $477 \%$. Não obstante, as movimentações de agosto e setembro de 2020 são $-1.631 \%$ e $-1.356 \%$, respectivamente, menores em comparação a 2019. No Gráfico 1 é possível visualizar o declínio nas entradas das imigrantes mulheres no país.

As consequências do fechamento temporário das fronteiras nacionais no mês de abril puderam ser observadas também na base de dados do Sistema de Registro 
Nacional Migratório (SisMigra) da Polícia Federal. De janeiro a setembro de 2020 foram registrados no Brasil um total de 67.979 imigrantes. Deste total, 43\% foram mulheres: venezuelanas, responsáveis por $51 \%$ dos registros, seguidas pelas haitianas, com $25 \%$ do fluxo. Apesar da queda nos números dos registros em $-51 \%$, em relação ao mesmo período em 2019 (132.442), observaram-se as mesmas proporções entre os registros de homens (56\%) e mulheres (44\%), similarmente entre as mulheres venezuelanas (51\%) e haitianas $(23 \%)$.

Os dados da Tabela 1 demonstram como a pandemia de Covid-19 tem afetado de forma significativa a chegada de mulheres imigrantes no país. Em outras palavras, podemos afirmar que, o fluxo migratório feminino, com tendência a crescimento no Brasil desde a segunda metade da presente década, sofreu forte declínio devido à pandemia. Se esse fluxo retornará aos índices dos anos anteriores ou se será permanente, ainda é uma pergunta aberta. Todavia, é possível alegar que o fechamento das fronteiras e a redução da entrada de mulheres imigrantes no país, principalmente das venezuelanas, conforme comprovado por números e reafirmado por pesquisas, provocam consequências profundas para a mobilidade feminina. Dentre as consequências, os estudos destacam que as imigrantes passaram a fazer uma travessia por caminhos menos conhecidos e menos seguros (Annoni, 2020; Foley \& Piper, 2020; UN Women, 2020). As vias pelas quais as migrantes em trânsito são impelidas a seguir amplificam suas situações de vulnerabilidade: são mais expostas à violência sexual, à exploração econômica por parte dos atravessadores, além de encontrarem adversidades para acessar serviços médicos, alimentação e abrigo (Wilges \& Soares, 2020). Essas autoras afirmam ainda que o fecha-

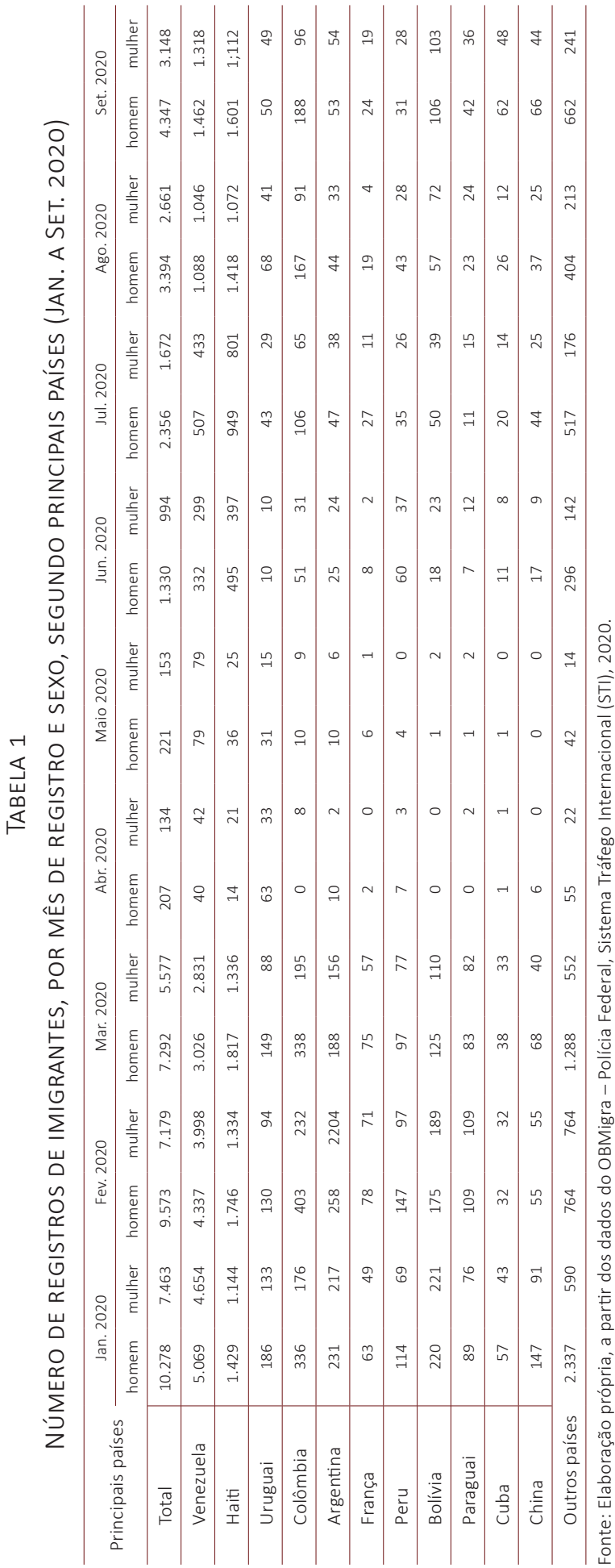


mento das fronteiras para as venezuelanas teve efeitos psicológicos significativos, sobretudo entre as que deixaram seus filhos na Venezuela e esperavam reencontrá-los em breve; reencontro agora incerto e imprevisível.

Essa seção, portanto, demonstrou, por meio da análise das movimentações nas fronteiras e dos registros, a redução na mobilidade das mulheres imigrantes, causada pela pandemia. Na próxima seção avançaremos na análise de dados sobre os impactos da pandemia para a inserção laboral das mulheres imigrantes no país.

\section{Análise das movimentações das mulheres imigrantes no mercado de trabalho formal}

Para além dos impactos nos fluxos migratórios, de chegada e de saída das mulheres imigrantes, a pandemia vem afetando a inserção laboral das imigrantes e até mesmo a permanência daquelas que já estavam inseridas. Como analisado por Tonhati e Macêdo (2020), entre os anos de 2010 e 2019 houve um crescimento exponencial na emissão de carteiras de trabalho para mulheres imigrantes. As autoras demonstraram que, em 2011, por exemplo, foram emitidas apenas 3.722 carteiras, contra 39.813 em 2019, ou seja, um aumento de $970 \%$. Por conseguinte, esse aumento na emissão de carteira de trabalho nos permite inferir que a busca por trabalho tem sido um dos principais objetivos das mulheres imigrantes no país.

Em termos de participação efetiva no mercado de trabalho formal, as autoras expuseram uma crescente inserção laboral de mulheres imigrantes entre 2010 e 2019. No entanto, esse aumento foi apenas em termos absolutos, pois, em termos relativos, o mercado formal de trabalho não absorveu por completo essa mão de obra.

Em 2019, foram emitidas 39.813 carteiras de trabalho para mulheres imigrantes no Brasil, no entanto, apenas 28.096 foram admitidas em algum tipo de emprego formal no mesmo ano. O que significa que 11.717 das mulheres que tiraram carteira de trabalho no ano de 2019 não exerceram nenhuma atividade no mercado de trabalho formal. De fato, o número de mulheres à procura de emprego no ano de 2019 pode ser ainda muito maior, já que as admissões feitas em 2019 não ocorreram apenas entre as mulheres que tiveram a CTPS emitida naquele ano (Tonhati \& Macêdo, 2020: 122).

Esses dados são relevantes para demonstrar que o cenário de inserção laboral para as mulheres imigrantes, de 2010 a 2019, tendia ao crescimento e com números de admissões sendo ampliados. Esses números foram fortemente afetados pela pandemia de Covid-19, e a tendência observada sofreu alteração, interrompendo a sua linha crescente. 
O número de imigrantes e de refugiados admitidos em 2019 (de janeiro a setembro) foi de 70.516, considerando homens (50.013) e mulheres (20.503). Nota-se que as mulheres imigrantes corresponderam a $29 \%$ do total de imigrantes admitidos no mercado de trabalho formal brasileiro. O saldo entre admissões e demissões nesse período foi de 15.017, o que significa que houve um saldo positivo de inserção laboral, com a criação de postos de trabalho que foram ocupados por imigrantes. 0 saldo positivo para mulheres foi de 4.674 .

Em contrapartida, quando analisamos os dados desse mesmo período (de janeiro a setembro), notamos claramente o impacto da pandemia na inserção laboral dos imigrantes, em geral, e, particularmente, para as mulheres imigrantes. No total, os admitidos em 2020 (Jan. a Set.) foram 57.547, representando uma queda de -18\%, em relação ao mesmo período de 2019 (70.516). Entre os homens, a redução foi de -14\% e para as mulheres, de $-28 \%$. O saldo entre admissões e demissões nesse período ficou em 14.865, o que significou uma queda de $-1 \%$ em relação ao mesmo período de 2019. Entre os homens, o saldo foi de 11.360 (2020) e 10.343 (2019), apresentando um aumento de $10 \%$ e, já para as mulheres, o saldo foi de 3.505 (2020) e 4.674 (2019), diminuindo em -25\% a presença das imigrantes no mercado de trabalho brasileiro formal em relação a 2019, conforme a Tabela 2 demonstra. As mulheres imigrantes, portanto, perderam mais postos de trabalho que os homens imigrantes, o que comprova que a inserção laboral das mulheres foi mais afetada pela pandemia.

No intuito de realizar uma análise mais profunda de quando a pandemia de Covid-19 começa a afetar as admissões e as demissões das imigrantes no mercado de trabalho formal no país, buscamos desintegrar os dados aqui analisados, mês a mês de 2020.

TABELA 2

MOVIMENTAÇÃO DE TRABALHADORAS IMIGRANTES NO MERCADO DE TRABALHO FORMAL, POR TIPO DE MOVIMENTAÇÃO E ANO, SEGUNDO O MÊS (JAN. A SET. 2019-2020)

\begin{tabular}{|c|c|c|c|c|c|c|c|}
\hline \multirow{2}{*}{$\begin{array}{l}\text { Mês de } \\
\text { movimentação }\end{array}$} & Admitidas & Demitidas & Admitidas & Demitidas & \multicolumn{3}{|c|}{ Saldo } \\
\hline & \multicolumn{2}{|c|}{ Jan. a Set. 2019} & \multicolumn{2}{|c|}{ Jan. a Set. 2020} & Jan. a Set. 2 & Jan. a Set. 2020 & Variação (\%) \\
\hline Total & 20.253 & 15.829 & 14.700 & 11.195 & 4.674 & 30.505 & $-25 \%$ \\
\hline Janeiro & 2.051 & 1.686 & 2.226 & 1.297 & 365 & 929 & $155 \%$ \\
\hline Fevereiro & 2.542 & 1.792 & 2.270 & 1.346 & 750 & 924 & $23 \%$ \\
\hline Março & 2.093 & 1.946 & 2.065 & 1.941 & 147 & 124 & $-16 \%$ \\
\hline Abril & 2.247 & 1.703 & 869 & 1.756 & 544 & -896 & $-265 \%$ \\
\hline Maio & 2.025 & 1.923 & 1.017 & 1.032 & 102 & -15 & $-115 \%$ \\
\hline Junho & 2.129 & 1.788 & 1.055 & 949 & 341 & 106 & $-69 \%$ \\
\hline Julho & 2.406 & 1.736 & 1.477 & 889 & 670 & 588 & $-12 \%$ \\
\hline Agosto & 2.537 & 1.639 & 1.730 & 924 & 898 & 806 & $-10 \%$ \\
\hline Setembro & 2.473 & 1.616 & 2.000 & 1.061 & 857 & 939 & $10 \%$ \\
\hline
\end{tabular}

Fonte: Elaboração própria, a partir dos dados do OBMigra, Ministério da Economia, base harmonizada Rais-CTPS-Caged, 2020. 
Observamos que, nos meses de janeiro e fevereiro de 2020, a inserção laboral das/ os imigrantes teve um saldo positivo e crescente, o que era uma tendência no ano de 2019. O impacto da pandemia, portanto, se inicia no mês de março, e tem sua maior expressão nos meses subsequentes - abril, maio e junho. Tal período coincide com as medidas de isolamento social mais rígidas em diversos estados do país.

O número de admissões nesses meses foi reduzido drasticamente. No mês de fevereiro de 2020, o saldo de contratações foi de 2.377, para homens e 924, para mulheres, esse número caiu brutalmente em março para 775 (homens) e 124 (muIheres), uma redução de $-67 \%$ e $-87 \%$ respectivamente. No entanto, nada se compara ao mês de abril, quando o saldo ficou negativo, retrato de mais demissões que admissões. A queda entre fevereiro de 2020, período ainda sem pandemia no país, e abril é de $-193 \%$, para homens e $-197 \%$, para mulheres, dados que indicam que os imigrantes, tanto homens quanto mulheres, perderam seus empregos durante esse período e enfrentam situação de maior vulnerabilidade. No mês de maio, o saldo continua negativo, mas com uma margem percentual de perda de empregos menor que a de abril. Em maio, o saldo ficou em -30 (-15 homens e -15 para mulheres), repetindo a tendência de mais demissões que admissões.

No mês de junho, há uma retomada das contratações de imigrantes e, assim, o mercado de trabalho formal volta a apresentar um saldo positivo para criação de postos de trabalho ocupados por imigrantes. No entanto, notamos que essa recuperação está ainda abaixo da tendência que vinha ocorrendo nos dois primeiros meses do ano e, ainda inferior, se comparado com junho de 2019 (-8\%, homens e -69\%, mulheres). Nesse cenário, novamente é possível observar como as mulheres imigrantes foram mais afetadas pela pandemia, visto que a retomada das admissões para elas não seguiu a mesma tendência que para os homens.

Os meses de agosto e setembro continuam com saldo positivo de contratações. Tal fato coincide com a reabertura de setores econômicos em diversos estados e cidades e demonstra que os imigrantes voltaram a ser contratados. Esse é um ponto de importante reflexão, pois, se, por um lado, voltaram a ser admitidos no mercado de trabalho formal, reduzindo a vulnerabilidade econômica dos imigrantes, por outro, constata-se que estão mais expostos à contaminação pela Covid-19.

Vimos, até agora, como a pandemia de Covid-19 afetou a inserção e a manutenção dos empregos das/os imigrantes de forma geral, principalmente, nos meses de abril, maio e junho de 2020, período de muitas demissões. A partir de agosto e setembro, os dados demonstram que os índices de contratações e demissões voltaram a ter um padrão semelhante ao de 2019. Para além dos dados gerais, 
TABELA 3

MOVIMENTAÇÃO DE TRABALHADORAS/ES IMIGRANTES

NO MERCADO DE TRABALHO FORMAL, POR MÊS E SEXO (JAN. A SET. 2020)

\begin{tabular}{l|rrrrrrrrrr}
\hline \multirow{2}{*}{ Mês } & \multicolumn{7}{|c}{ Total } & \multicolumn{7}{c}{ Jan.-Set. 2020 } \\
\cline { 2 - 11 } & \multicolumn{3}{|c}{} & \multicolumn{7}{|c}{ Homens } \\
\cline { 2 - 11 } & Admitidos & Demitidos & Saldo & Admitidos & Demitidos & Saldo & Admitidos & Demitidos & Saldo \\
\hline Total & 57.547 & 42.682 & 14.865 & 42.847 & 31.487 & 11.360 & 14.700 & 11.195 & 3.505 \\
\hline Janeiro & 8.299 & 4.849 & 3.450 & 6.073 & 3.552 & 2.521 & 2.226 & 1.297 & 929 \\
\hline Fevereiro & 8.457 & 5.156 & 3.301 & 6.187 & 3.810 & 2.377 & 2.270 & 1.346 & 924 \\
\hline Março & 7.770 & 6.871 & 899 & 5.705 & 4.930 & 775 & 2.065 & 1.941 & 124 \\
\hline Abril & 3.248 & 6.364 & -3.116 & 2.388 & 4.608 & -2.220 & 860 & 1.756 & -896 \\
\hline Maio & 3.967 & 3.997 & -30 & 2.950 & 2.965 & -15 & 1.017 & 1.032 & -15 \\
\hline Junho & 4.725 & 3.739 & 986 & 3.670 & 2.790 & 880 & 1.055 & 949 & 106 \\
\hline Julho & 6.013 & 3.522 & 2.941 & 4.536 & 2.633 & 1.903 & 1.477 & 889 & 588 \\
\hline Agosto & 7.176 & 3.808 & 3.368 & 5.446 & 2.884 & 2.562 & 1.730 & 924 & 806 \\
\hline Setembro & 7.892 & 4.376 & 3.516 & 5.892 & 3.315 & 2.577 & 2.000 & 1.061 & 939 \\
\hline
\end{tabular}

Fonte: Elaboração própria, a partir dos dados do OBMigra, Ministério da Economia, base harmonizada Rais-CTPS-Caged, 2020.

também procuramos neste artigo usar uma lupa de aproximação com o intuito de verificarmos quais as nacionalidades mais atingidas, de refletirmos sobre as características das mulheres imigrantes no mercado de trabalho formal no país em 2020 e apresentarmos os seus principais nichos laborais e de renda.

Análises dos impactos da pandemia de Covid-19

para mulheres imigrantes, por nacionalidade e Unidades da Federação

Em 2019, no período estudado as/os haitianas/os representaram a nacionalidade com o maior número de admissões (23.995), sendo 18.358 para os homens e 5.637 para as mulheres. Não obstante, no saldo de contratações, os haitianos ficaram -30\% abaixo dos venezuelanos, já que os haitianos foram mais demitidos. O saldo para os haitianos foi de 5.782 (4.197 homens e 1.585 mulheres). Os venezuelanos foram menos admitidos, 14.131, mas tiveram um saldo mais positivo 8.278 (homens 6.033 e mulheres 2.245), demonstrando que eles sofreram com menos demissões. No ano de 2020, os haitianos continuaram sendo os mais admitidos (24.788) e os venezuelanos se posicionaram em segundo lugar (18.818). Ambas as nacionalidades apresentaram um saldo positivo de contratações, haitianos totalizando 8.286 (6.540 homens e 1.746 mulheres) e venezuelanos totalizando 8.258 (5.916 homens e 2.342 mulheres).

No mês de abril de 2020, período de maiores demissões, todas as nacionalidades foram afetadas. As haitianas e os haitianos foram os que mais sofreram com as de- 
missões no mês de abril, no total foram -1.359 (-1.009 homens e-350 mulheres), subsequentemente, os venezuelanos, com um saldo de $-127 \%$ menor (-256 saldo) em relação ao mesmo período em 2019. No entanto, essas duas nacionalidades, tanto para mulheres quanto para homens, conseguiram voltar aos patamares de admissão e obtiveram saldos positivos no período analisado. A saber, os haitianos superaram o saldo de 2019 desse período em 43\%, ou seja, mais postos de trabaIho foram criados para as haitianas e os haitianos em 2020 (8.286 - homens 5.336 e mulheres 1.746), comparado a 2019 (5.782 - homens 4.161 e mulheres 1.585).

Entre os venezuelanos, o saldo de 2019 (8.278 - homens 6.033 e mulheres 2.245) e 2020 (8.258 - homens 5.916 e mulheres 2.342) foram semelhantes tanto para homens como para mulheres. É relevante observar que, em 2019, apesar de as/os haitianas/os serem mais admitidas/os que as/os venezuelanas/os, também sofreram com mais demissões, apresentando saldo inferior ao das/dos venezuelanas/os. Em 2020, o saldo para as/os haitianas/os foi maior em apenas 0,3\%.

No que tange às mulheres, especificamente, podemos notar uma importante diferença entre as haitianas e venezuelanas. Em 2019, por exemplo, foram 5.637 admissões para haitianas e 4.052 demissões; por sua vez, entre as venezuelanas, foram 3.943 admissões e 1.698 demissões. As venezuelanas, naquele ano, apesar de terem sido menos admitidas no mercado de trabalho formal, também foram menos demitidas, o que demonstrou uma menor rotatividade de emprego e de demissões entre as venezuelanas em relação às haitianas. Em 2020, os índices de contratações entre as venezuelanas e haitianas ficaram muito próximos (5.360 e 5.336 respectivamente), entretanto, notamos que as venezuelanas passaram as haitianas em termos de contratação e continuaram apresentando um saldo mais positivo (2.342) em termos de criação de postos de trabalho, em comparação às haitianas (1.746).

Ao observar outras oito principais nacionalidades inseridas no mercado de trabaIho formal do país, constatamos que a pandemia de Covid-19 causou queda na

TABELA 4

MOVIMENTAÇÃO DE TRABALHADORAS/ES IMIGRANTES NO MERCADO DE TRABALHO FORMAL, POR MÊS E SEXO, SEGUNDO HAITI E VENEZUELA (JAN. A SET. 2019-2020)

\begin{tabular}{|c|c|c|c|c|c|c|c|c|c|c|c|c|}
\hline \multirow{3}{*}{ País } & \multicolumn{6}{|c|}{ Jan.-Set. 2019} & \multicolumn{6}{|c|}{ Jan.-Set. 2020} \\
\hline & \multicolumn{3}{|c|}{ Homens } & \multicolumn{3}{|c|}{ Mulheres } & \multicolumn{3}{|c|}{ Homens } & \multicolumn{3}{|c|}{ Mulheres } \\
\hline & Admitidos & Demitidos & Saldo & Admitidos & Demitidos & Saldo & Admitidos & Demitidos & Saldo & Admitidos & Demitidos & Saldo \\
\hline Total & 50.013 & 39.370 & 10.343 & 20.503 & 15.829 & 4.674 & 42.847 & 31.487 & 11.360 & 14.700 & 11.195 & 3.505 \\
\hline Haiti & 18.358 & 14.171 & 4.197 & 5.637 & 4.052 & 1.585 & 19.452 & 12.912 & 6.540 & 5.336 & 3.590 & 1.746 \\
\hline Venezuela & 10.188 & 4.156 & 6.033 & 3.943 & 1.698 & 2.245 & 13.458 & 7.542 & 5.916 & 5.360 & 3.018 & 2.342 \\
\hline Outros & 50.013 & 39.670 & 10.343 & 20.503 & 15.829 & 4.674 & 42.847 & 31.487 & 11.360 & 14.700 & 11.185 & 3.505 \\
\hline
\end{tabular}

Fonte: Elaboração própria, a partir dos dados do OBMigra, Ministério da Economia, base harmonizada Rais-CTPS-Caged, 2020. 
TABELA 5

MOVIMENTAÇÃO DOS TRABALHADORAS/ES IMIGRANTES NO MERCADO DE TRABALHO FORMAL, POR MÊS E SEXO, SEGUNDO OS PRINCIPAIS PAÍSES, EXCETO HAITI E VENEZUELA (JAN. A SET. 2019-2020)

\begin{tabular}{|c|c|c|c|c|c|c|c|c|c|c|c|c|}
\hline \multirow{3}{*}{$\begin{array}{l}\text { Principais } \\
\text { países }\end{array}$} & \multicolumn{6}{|c|}{ Jan.-Set. 2019} & \multicolumn{6}{|c|}{ Jan.-Set. 2020} \\
\hline & \multicolumn{3}{|c|}{ Homens } & \multicolumn{3}{|c|}{ Mulheres } & \multicolumn{3}{|c|}{ Homens } & \multicolumn{3}{|c|}{ Mulheres } \\
\hline & Admitidos & Demitidos & Saldo & Admitidos & Demitidos & Saldo & Admitidos & Demitidos & Saldo & Admitidos & Demitidos & Saldo \\
\hline Total & 50.013 & 39.370 & 10.343 & 20.503 & 15.829 & 4.674 & 42.847 & 31.487 & 11.360 & 14.700 & 11.195 & 3.505 \\
\hline Argentina & 1.899 & 1.775 & 114 & 1.223 & 1.146 & 77 & 852 & 891 & -39 & 439 & 552 & -113 \\
\hline Paraguai & 1.565 & 1.535 & 30 & 817 & 724 & 93 & 890 & 873 & 17 & 458 & 497 & -39 \\
\hline Bolívia & 1.351 & 781 & 570 & 876 & 472 & 404 & 821 & 894 & -73 & 381 & 482 & 101 \\
\hline Cuba & 1.011 & 1.344 & -333 & 431 & 577 & -146 & 948 & 710 & 238 & 361 & 325 & 36 \\
\hline Uruguai & 967 & 1.003 & -36 & 658 & 700 & -42 & 495 & 601 & -106 & 278 & 337 & -59 \\
\hline Peru & 1.105 & 897 & 208 & 515 & 453 & 62 & 535 & 654 & -119 & 250 & 249 & 1 \\
\hline Senegal & 866 & 956 & -90 & 303 & 318 & -15 & 724 & 762 & -38 & 25 & 20 & 5 \\
\hline Portugal & 9.905 & 10.422 & -517 & 4.175 & 3.911 & 264 & 381 & 601 & -220 & 126 & 217 & -91 \\
\hline Outros & 38.451 & 28.738 & 9.713 & 13.755 & 9.661 & 4.094 & 37.201 & 25.501 & 11.700 & 12.382 & 8.516 & 3.866 \\
\hline
\end{tabular}

Fonte: Elaboração própria, a partir dos dados do OBMigra- Ministério da Economia, base harmonizada Rais-CTPS-Caged, 2020.

empregabilidade e não houve retomada na inserção laboral. A constatação de que os saldos de movimentações do ano de 2019 não retornaram aos patamares antes atingidos engloba mulheres e homens da Argentina, do Paraguai, da Bolívia, de Cuba, do Uruguai, do Peru, do Senegal e de Portugal.

Entre as Unidades da Federação (UFs) que tiveram maior redução no saldo de criação de postos de trabalho para mulheres imigrantes destacou-se a Região Sudeste, que, em 2019, teve um saldo positivo de 1.292; em 2020, apresentou um saldo negativo de -119. Outra região que apresentou saldo negativo foi a Nordeste de -35. As Regiões Norte e Centro-Oeste tiveram redução no saldo das contratações, contudo, mantiveram mais admissões que demissões. A exceção foi a Região Sul, onde houve aumento no saldo em relação a 2019, passando de 2.349, para 3.033.

Os números chamam atenção para o saldo negativo (-208) no estado de São Paulo, estado que, desde 2011, apresentava saldo positivo nas movimentações para mulheres imigrantes no mercado de trabalho formal. Deve-se observar ainda que, no estado de Santa Catarina, os números apontam aumento de postos de trabalho para as mulheres imigrantes, durante a pandemia (1.719). Essas variações podem ser mais compreendidas quando atentamos para os nichos laborais que foram mais afetados e os que engendraram crescimento nas contratações de 2020. Esses dados serão analisados na próxima subseção. 
TABELA 6

MOVIMENTAÇÃO DAS TRABALHADORAS IMIGRANTES NO MERCADO DE TRABALHO FORMAL, POR MÊS, SEGUNDO GRANDES REGIÕES E UFS (JAN. A SET. 2020)

\begin{tabular}{|c|c|c|c|}
\hline \multirow{2}{*}{ Brasil, Regiões e UFs } & \multicolumn{3}{|c|}{ Jan.-Set. 2020} \\
\hline & Admitidos & Demitidos & Saldo \\
\hline Brasil & 14.700 & 11.195 & 3.505 \\
\hline Norte & 807 & 625 & 182 \\
\hline Rondônia & 71 & 65 & 6 \\
\hline Acre & 10 & 7 & 3 \\
\hline Amazonas & 367 & 262 & 105 \\
\hline Roraima & 329 & 264 & 105 \\
\hline Pará & 24 & 21 & 3 \\
\hline Amapá & 2 & 1 & 1 \\
\hline Tocantins & 4 & 5 & -1 \\
\hline Nordeste & 260 & 295 & -33 \\
\hline Maranhão & 9 & 4 & 5 \\
\hline Piauí & 2 & 3 & -1 \\
\hline Ceará & 43 & 62 & -19 \\
\hline Rio Grande do Norte & 16 & 20 & -4 \\
\hline Paraíba & 11 & 17 & -6 \\
\hline Pernambuco & -31 & 43 & -12 \\
\hline Alagoas & 12 & 9 & 3 \\
\hline Sergipe & 6 & 9 & -3 \\
\hline Bahia & 139 & 128 & 2 \\
\hline Sudeste & 4.361 & 4.480 & -119 \\
\hline Minas Geais & 609 & 434 & 175 \\
\hline Espírito Santo & 21 & 32 & -11 \\
\hline Rio de Janeiro & 168 & 243 & -75 \\
\hline São Paulo & 3.563 & 3.771 & -208 \\
\hline Sul & 7.872 & 4.839 & 3.033 \\
\hline Paraná & 1.988 & 1.319 & 669 \\
\hline Santa Catarina & 3.762 & 2.043 & 1.719 \\
\hline Rio Grande do Sul & 2.122 & 1.477 & 645 \\
\hline Centro-Oeste & 1.371 & 952 & 419 \\
\hline Mato Grosso do Sul & 611 & 325 & 268 \\
\hline Mato Grosso & 353 & 279 & 74 \\
\hline Goiás & 241 & 171 & 70 \\
\hline Distrito Federal & 166 & 177 & -11 \\
\hline
\end{tabular}

Fonte: Elaboração própria, a partir dos dados do OBMigra, Ministério da Eco nomia, base harmonizada Rais-CTPS-Caged, 2020. (1.266), em terceiro faxineira (272) e, na sequência, operadora de caixa (165).

Os dados demonstram que os setores de serviços como um todo tiveram saldo negativo, ou seja, houve mais demissões que contratações em ocupações como: auxiliar nos serviços de alimentação em restaurantes, lanchonetes e hotéis (-120),

Análises dos impactos da pandemia de Covid-19 para mulheres imigrantes, por nichos laborais e renda

Ao desagregar os dados por nichos laborais, no intuito de analisar qual grupo de muIheres imigrantes tem sido mais afetado pela pandemia de Covid-19, notamos que as admissões diminuíram para todos os grupos ocupacionais, entretanto, claramente, os setores que estavam vinculados a serviços foram os que menos contrataram. Em 2019, o saldo das cinco principais ocupações que as imigrantes mulheres exerciam no mercado de trabalho formal foi: alimentadora de linha de produção (666), magarefe (523), faxineira (488), auxiliar nos serviços de alimentação (296) e auxiliar de escritório (170). Em 2020, a ocupação de vendedora de comércio varejista foi a que sofreu o maior decréscimo, passando a ocupar o quinto lugar entre as ocupações. A primeira ocupação tornou-se alimentadoras de linha de produção (1.109), em segundo lugar magarefe 
vendedora de comércio varejista (-63), cozinheira (-55) e atendente de lanchonete (-35). Em contraposição, as linhas de produção em setores alimentícios e abate de animais (aves e suínos) se tornaram nichos laborais relevantes para a empregabilidade das imigrantes mulheres, com um saldo positivo de contratações, surpreendentemente apresentando aumento em relação ao ano de 2019: as profissões de alimentadora de linha de produção e magarefe tiveram aumento no saldo das movimentações de $67 \%$ e $142 \%$, respectivamente.

Nesse ponto devemos ressaltar o impacto da pandemia de Covid-19 e os paradoxos que sofrem as imigrantes. A pandemia, aliada a outros fatores como a desvalorização do real, fizeram com que atividades laborais relacionadas ao abate de suínos e aves aumentassem a procura por mão de obra, o que levou ao aumento da empregabilidade de imigrantes mulheres nesse setor. Como consequência, também as tornou mais expostas à contaminação pelo novo coronavírus, considerando que as condições laborais nesses espaços são insalubres, o trabalho é realizado em espaço fechado e as trabalhadoras ficam próximas umas das outras na linha de produção.

Reportagens como as de Camilla Veras Mota (BBC), de 2 de julho de 2020, ressaltaram como o ambiente frio e úmido dos frigoríficos e o barulho das máquinas leva as/os trabalhadoras/es a falarem alto, o que favorece a disseminação do novo coronavírus nesses ambientes. A reportagem traz o ocorrido na cidade de Xaxim, em Santa Catarina, onde o aumento do número de casos ocorreu devido às transmissões nos frigoríficos. Dentre os contaminadas/os, as/os imigrantes apareceram como s/os mais vulneráveis, pois, muitas vezes compartilham habitações que são, em alguns casos, alojamentos da própria empresa, em outros, casas alugadas nas quais convivem vários imigrantes e, até mesmo, famílias. Desse modo, a transmissão do vírus se torna mais rápida, devido à impossibilidade de se aplicar qualquer tipo de isolamento social. A reportagem relata, ainda, o óbito de um imigrante haitiano.

Notamos, portanto, que o aumento da empregabilidade de mulheres imigrantes durante o período de pandemia, em locais como frigorífico, resultou na exposição das trabalhadoras ao vírus e na possibilidade de contraírem a doença. Diante dessa constatação, é possível afirmar que o crescimento da inserção laboral de mulheres imigrantes no trabalho de abate de aves e suínos levou a um significativo impacto na pandemia. As consequências desse trabalho para a saúde das mulheres imigrantes, em termos físicos, sociais e psicológicos, devem ser aprofundadas em estudos qualitativos. Entretanto, é possível, por meio dos dados aqui apresentados, afirmar que a migração feminina no Brasil adentra nichos laborais que não são investigados pela literatura hegemônica sobre o tema, como ressaltado na introdução deste artigo. Buscar entender as razões da empregabilidade de mulheres imigrantes nesses 
TABELA 7

MOVIMENTAÇÃO DAS TRABALHADORAS IMIGRANTES NO MERCADO DE TRABALHO FORMAL, POR MÊS, SEGUNDO PRINCIPAIS OCUPAÇÕES (JAN. A SET. 2019-2020)

\begin{tabular}{|c|c|c|c|c|c|c|}
\hline \multirow{2}{*}{ Principais atividades econômicas } & \multicolumn{3}{|c|}{ Jan.-Set. 2019} & \multicolumn{3}{|c|}{ Jan.-Set. 2020} \\
\hline & Demitidos & Demitidos & Saldo & Demitidos & Demitidos & Saldo \\
\hline Total & 20.503 & 15.829 & 4.674 & 14.700 & 11.195 & 3.505 \\
\hline Restaurante e similares & 1.671 & 1.403 & 268 & 783 & 1.096 & -313 \\
\hline Abate de aves & 976 & 443 & 533 & 1.852 & 444 & 1.408 \\
\hline Lanchonetes, casas de chá, de sucos e similares & 727 & 597 & 130 & 342 & 427 & -85 \\
\hline Hotéis & 617 & 627 & -10 & 243 & 511 & -268 \\
\hline Comércio varejista de artigos do vestuário e acessórios & 566 & 553 & 13 & 237 & 332 & -95 \\
\hline $\begin{array}{l}\text { Comércio varejista de mercadorias em geral, com predomi- } \\
\text { nância de produtos alimentícios, supermercados }\end{array}$ & 614 & 493 & 121 & 653 & 382 & 271 \\
\hline $\begin{array}{l}\text { Confecção de peças do vestuário, exceto roupas íntimas e as } \\
\text { confeccionadas sob medida }\end{array}$ & 579 & 466 & 113 & 280 & 319 & -39 \\
\hline Frigorífico, abate de suínos & 693 & 265 & 428 & 1.188 & 285 & 903 \\
\hline Limpeza em prédios e em domicílios & 491 & 464 & 27 & 342 & 276 & 66 \\
\hline Ensino de idiomas & 360 & 306 & 54 & & & \\
\hline Locação de mão de obra temporária & & & & 433 & 398 & 35 \\
\hline Outros & 13.209 & 10.212 & 2.997 & 8.347 & 6.725 & 1.622 \\
\hline
\end{tabular}

Fonte: Elaboração própria, a partir dos dados do OBMigra, Ministério da Economia, base harmonizada Rais-CTPS-Caged, 2020.

espaços, as suas condições laborais, as particularidades que envolvem o trabalho (horas trabalhadas, remuneração, descanso/férias, maternidade, entre outros) são aspectos relevantes para melhor compreender as migrações femininas.

Por fim, também analisamos se houve alterações no rendimento médio das imigrantes admitidas no mercado de trabalho formal, devido a pandemia de Covid-19. Dados apresentados por Tonhati e Macêdo (2020) demonstraram que os eixos sociais de desigualdade como gênero, classe, raça e países de origem estão inter-relacionados com as diferenças de rendimentos das imigrantes. Ao analisar a série histórica de 2010 a 2019, as autoras encontraram diversos elementos que marcaram a diferença de rendimentos entre homens e mulheres e destacaram que os homens imigrantes ganhavam praticamente o dobro das mulheres imigrantes, em 2011, e essa diferença só veio a diminuir a partir de 2013, devido à chegada dos imigrantes haitianos e, posteriormente, venezuelanos. As mulheres imigrantes tiveram uma média de rendimentos menor que os homens imigrantes em todos os anos, de 2011 a 2019. Destaca-se que essa aproximação nos rendimentos não se deu por um movimento em busca de direitos por rendimentos igualitários, mas por uma maior inserção laboral dos imigrantes em ocupações de baixa remuneração.

Os dados de 2019, analisados por Tonhati e Macêdo (2020), demonstraram ainda que há grandes diferenças entre as nacionalidades. Os homens imigrantes, com os maiores rendimentos em 2019, provinham dos países do Norte Global. O mesmo ocorreu entre as mulheres. Entretanto, foi observado pelas autoras que, 
[...] mesmo entre os maiores rendimentos e sendo provenientes das regiões mais ricas, há uma grande diferença entre os rendimentos de homens e mulheres imigrantes. Somando os rendimentos das dez primeiras nacionalidades de homens imigrantes foi possível constatar que esses ganham $50 \%$ a mais que a soma das dez primeiras nacionalidades de mulheres imigrantes com maiores rendimentos, demonstrando que há desigualdade de gênero na inserção laboral mesmo entre os imigrantes provenientes de países ricos (Tonhati \& Macêdo, 2020: 134).

Foi ainda constatada desigualdade de rendimentos entre as mulheres do Norte Global e as do Sul Global; a maioria de mulheres dos países ricos do Norte Global tendem a ganhar $80 \%$ mais que as imigrantes mulheres dos países pobres do Sul Global. A pandemia de Covid-19 pouco alterou os rendimentos médios entre as mulheres imigrantes no momento de sua admissão. Assim como em 2019, no ano de 2020 as fortes desigualdades salariais mantiveram-se, influenciadas pelas variáveis de sexo e país de origem.

Os homens imigrantes, provenientes dos países ricos do Norte Global continuam ganhando em média $47,5 \%$ a mais que as mulheres com os maiores rendimentos, que também, majoritariamente, são provenientes de países ricos. A diferença salarial entre homens e mulheres imigrantes originárias dos países pobres do Sul Global é bem menor, apenas 0,23\%. Por sua vez, a diferença salarial entre as mulheres, que embolsam os dez maiores rendimentos, do Norte Global, e as dos dez menores rendimentos, oriundas do Sul Global, é de $79 \%$.

A pandemia de Covid-19 pouco alterou o quadro de desigualdade já constatado em 2019. A análise contínua e comparativa dos dados (2011 a 2020) permitiu-nos observar que as haitianas, as venezuelanas, as paraguaias, as bolivianas, as cubanas, as ganenses, as senegalesas, as bengalis, as dominicanas e as angolanas continuaram entre as dez principais nacionalidades com maior empregabilidade no mercado de trabalho formal no país, mas também com os menores rendimentos salariais. Assim, podemos inferir que a maioria das mulheres imigrantes no Brasil está sendo inserida em nichos laborais de baixa remuneração. Aqui, gostaríamos de enfatizar que acreditamos que a variável raça/cor influencia da mesma forma a inserção laboral e os rendimentos dessas mulheres. No entanto, os dados disponíveis nas bases analisadas não nos permitem ratificar essa correlação.

Para comprovar essa correlação, é preciso estudos mais específicos e aprofundados nessa direção, como, por exemplo, o estudo realizado por Jeane Souza e equipe (2020, p. 6), que, a partir de dados qualitativos, demonstra que as vulne- 
TABELA 8

RENDIMENTO MÉDIO DE ADMISSÃO DAS

TRABALHADORAS IMIGRANTES NO

MERCADO DE TRABALHO FORMAL,

SEGUNDO NACIONALIDADE (JAN. A SET. 2020)*

\begin{tabular}{|c|c|}
\hline \multicolumn{2}{|c|}{ Países com rendimento médio mais baixo } \\
\hline \multirow{2}{*}{ País } & Jan. a Set. 2020 \\
\hline & Rendimento médio \\
\hline Total & 1.767 \\
\hline Gana & 1.300 \\
\hline Haiti & 1.306 \\
\hline Bangladesh & 1.312 \\
\hline Venezuela & 1.354 \\
\hline República Dominicana & 1.404 \\
\hline Senegal & 1.406 \\
\hline República Democrática do Congo & 1.444 \\
\hline Cuba & 1.444 \\
\hline Angola & 1.520 \\
\hline Paraguai & 1.541 \\
\hline Outros & 3.519 \\
\hline
\end{tabular}

\begin{tabular}{|c|c|}
\hline \multicolumn{2}{|c|}{ Países com rendimento médio mais elevado } \\
\hline \multirow{2}{*}{ País } & Jan. a Set. 2020 \\
\hline & Rendimento médio \\
\hline Total & 1.767 \\
\hline França & 8.551 \\
\hline México & 8.203 \\
\hline Reino Unido & 7.728 \\
\hline Estados Unidos & 7.663 \\
\hline Espanha & 7.340 \\
\hline Alemanha & 6.287 \\
\hline Rússia & 5.730 \\
\hline Itália & 5.117 \\
\hline África do Sul & 5.115 \\
\hline Coreia do Sul & 5.008 \\
\hline Outros & 1.592 \\
\hline
\end{tabular}

* Os rendimentos médios apresentados foram deflacionados, pelo índice Nacional de Preços ao Consumidor (INPC) com relação a setembro de 2020. Em termos da seleção dos países apresentados na Tabela 8, foram considerados os países com ao menos 10 admissões no período aqui estudado. Ademais, para a consolidação dos dados, foram desconsiderados os registros intermitentes e os registros com salário declarado abaixo de 0,3 salário mínimo e acima de 150 salários mínimos.

Fonte: Elaboração própria, a partir dos dados do OBMigra, Ministério da Economia, base harmonizada Rais-CTPS-Caged, 2020. principais preocupações das imigrantes. Jeanne Souza e equipe (2020: 10), por exemplo, relata que, para as haitianas, a falta de emprego somada ao "preconceito, à fome, à falta de creche para os filhos e aos escassos recursos econômicos" estão rabilidades vivenciadas pelas mulheres imigrantes negras haitianas, no contexto da pandemia de Covid-19, tendem a aumentar. As autoras ressaltam que as imigrantes haitianas são geralmente pobres, estão em subempregos com desvantagens competitivas, "em virtude do racismo, da adaptação cultural, linguística e de acesso a informações, com escasso conhecimento de seus direitos no território brasileiro".

Ao analisarmos, portanto, os dados disponíveis sobre a inserção laboral das mulheres imigrantes no ano de 2020, ficou claro que a pandemia de Covid-19 reduziu a incorporação dessas mulheres no mercado de trabalho formal no país. Em suma, as admissões diminuíram em relação a 2019 e houve mais demissões em nichos laborais vinculados às áreas de serviços, com destaque para a redução desses postos de trabalho no estado de São Paulo, e um aumento nas admissões em setores vinculados aos frigorífiCatarina. Consequentemente, a falta de trabalho (redução das admissões e aumento das demissões) pode ser listada como sendo um dos principais impactos da pandemia de Covid-19 para as mulheres imigrantes, que até antes de 2020, vinham galgando cada vez mais postos de trabalho.

Outras pesquisas também ressaltam o desemprego como sendo uma das cos, principalmente, no estado de Santa 
entre os principais desafios enfrentados durante a pandemia de Covid-19. As autoras Leticia Wilges e Sandra Soares (2020), da mesma forma, demonstraram que, entre as venezuelanas, o desemprego foi o principal desafio e a maior preocupação durante a pandemia. Diante da necessidade de procurar emprego para o provimento de suas famílias e, ainda, de enviar remessas financeiras para auxiliar os familiares nos países de origem, podemos afirmar que as imigrantes ficam extremamente expostas à contaminação pelo vírus e, ainda, aos desdobramentos psicológicos do paradoxo da necessidade do isolamento social e do trabalho. O estudo de Souza e equipe (2020) relata que a pandemia tem provocado um aumento nas situações de estresse, frustração e ansiedade entre mulheres imigrantes.

\section{Considerações finais}

Como destacamos na introdução deste artigo, os debates teóricos em relação às migrações internacionais contemporâneas de mulheres, que se concentraram em analisar as migrações Sul-Norte, apontam para uma feminização das migrações. O aumento no número de mulheres imigrantes no Brasil também foi observado nos últimos cinco anos, e esse aumento decorre de um incremento nas migrações dos países do Sul-Global para o país. No Brasil, as imigrações, a partir de 2010, foram majoritariamente masculinizadas: dentre os postos de trabalho ocupados por imigrantes no país, os homens ocupam a maior parcela. Entretanto, o número de mulheres imigrantes no mercado de trabalho formal vinha aumentando nos últimos cinco anos. Essas mulheres imigrantes têm o perfil de serem jovens, com nível de instrução de ensino médio completo, provenientes dos países do Sul Global (haitianas, venezuelanas, cubanas e paraguaias), que estão em busca de emprego.

Portanto, é preciso destacar que, em termos dos debates acadêmicos (teóricos e empíricos) sobre as migrações internacionais no Brasil, até a primeira metade dessa década, a grande novidade foi a chegada de novos fluxos migratórios do Sul Global, que superaram os fluxos tradicionais, como, por exemplo, os portugueses (Cavalcanti et al., 2016); a partir da segunda metade da década (2015), figura-se como novidade o aumento no número de mulheres imigrantes chegando ao país, com grande destaque para as venezuelanas e as haitianas, que passaram a compor o mercado de trabalho formal. Nesse sentido, os dados sobre as imigrantes mulheres no Brasil têm revelado que elas ocupam diversos nichos laborais (por exemplo: frigoríficos), que extrapolam os protocolos de cuidado e reprodução. Esse dado possibilita a ampliação e contribui para o debate sobre as migrações femininas, bem como chama atenção para um olhar que desnuda as dificuldades e as desigualdades enfrentadas nesses espaços. 
No entanto, o ano de 2020, devido à pandemia de Covid-19, marca uma ruptura nessa tendência de crescimento do fluxo de mulheres imigrantes para o Brasil e os eventos relacionados à pandemia também dificultaram a inserção e a manutenção das imigrantes em empregos formais. Os dados do STI e do SisMigra, aqui apresentados, possibilitaram-nos ter um panorama analítico para responder sobre os impactos da pandemia na mobilidade das mulheres imigrantes. Em síntese, houve queda na entrada de mulheres imigrantes em todos os meses de 2020, em comparação a 2019. O mês de abril marcou o início do impacto da pandemia na mobilidade migratória das mulheres nas fronteiras brasileiras, com uma redução drástica em comparação aos meses anteriores. Posteriormente, com queda brusca em abril e maio, as chegadas mantiveram uma tendência de baixa, mas sem reduções abruptas.

Já em relação aos impactos da pandemia de Covid-19 na inserção e permanência das mulheres imigrantes no mercado de trabalho formal brasileiro, os dados analisados demonstraram que se de 2010 a 2019 o mercado de trabalho no país vinha admitindo mais imigrantes mulheres, com a persistência da pandemia, essa tendência sofreu alteração e interrompeu a sua linha de crescimento. As mulheres imigrantes perderam mais postos de trabalho que os homens imigrantes. Houve uma diminuição em -25\% na presença de imigrantes mulheres no mercado de trabalho brasileiro formal em 2020, em comparação a 2019. As haitianas e as venezuelanas foram as que mais sofreram com as demissões no mês de abril, que foi marcado por fortes medidas de isolamento social e fechamento de setores de serviços. Houve também impactos nos nichos laborais ocupados pelas imigrantes mulheres. Em 2020, a ocupação de vendedora de comércio varejista foi a que sofreu o maior decréscimo. Alimentadora de linha de produção destacou-se como a primeira ocupação; em segundo lugar, despontou-se magarefe e, em terceiro, bem abaixo das duas anteriores, faxineira. No ano de 2020 as fortes desigualdades salariais perpetuaram-se, dirigidas pelas variáveis de sexo e país de origem.

Desse modo, é possível concluir que as mulheres imigrantes no Brasil, em 2020, sofreram mais com os impactos da pandemia de Covid-19, quando comparadas aos homens imigrantes, em termos de mobilidade nas fronteiras e inserção laboral. A mobilidade das mulheres imigrantes nas fronteiras foi fortemente reduzida, o que gera uma maior exposição às situações de vulnerabilidade como: exploração econômica por atravessadores, violência sexual, entraves para acessar serviços de saúde, alimentação e abrigo. Ademais, vimos que as mulheres imigrantes sofreram com o desemprego, principalmente as venezuelanas, que trabalhavam em sua maioria em setores de comércio e restaurantes. No que se refere às haitianas, constatamos que não foram tão afetadas com o desemprego, porém, realizavam, em sua maioria, atividades que as deixavam muito suscetíveis à contaminação pela Covid-19. A falta 
de emprego e a exposição à possível contaminação pelo vírus são, portanto, os principais impactos da pandemia de Covid-19 para as mulheres imigrantes.

Por fim, os dados analisados nos permitiram a construção de um panorama sobre alguns desdobramentos da pandemia de Covid-19 sobre as mulheres imigrantes no país. Contudo, muitas indagações ainda esperam por análise, principalmente devido ao fato de a pandemia ainda estar em curso e não sabermos quando e como terminará. Este artigo, portanto, contribui para avançarmos no debate sobre as migrações femininas no Brasil na adversidade trazida pelo novo coronavírus.

\section{Referências}

ANDRADE, Cristiane Batista; BITENCOURT, Maria Silva; SANTOS, Daniela Lacerda; VEDOVATO, Tatiana Giovanelli. Venezuelanas no Brasil: trabalho e gênero no contexto da Covid-19. In: BAENINGER, Rosana; VEDORATO, Luís Renato; NANDY, Sailen (Coords.). VON ZUBEN, Catarina; MAGALHÃES, Luis Felipe; PARISE, Paolo; DEMÉTRIO, Natália; DOMENICONI, Joice (Orgs). Migrações internacionais e a pandemia de Covid-19, p. 426-435. Campinas: Núcleo de estudos de população "Elza Berquó" (Nepo/Unicamp), 2020.

ANNONI, Danielle. Mulheres migrantes e pandemia: vulnerabilidades sobrepostas diante da securitização internacional de fronteiras. In: BAENINGER, Rosana; VEDORATO, Luís Renato; NANDY, Sailen (Coords.). VON ZUBEN, Catarina; MAGALHÃES, Luis Felipe; PARISE, Paolo; DEMÉTRIO, Natália; DOMENICONI, Joice (Orgs.). Migrações internacionais e a pandemia de Covid-19, p. 323-336. Campinas: Núcleo de estudos de população "Elza Berquó" (Nepo/Unicamp), 2020.

ASSIS, Glaúcia. Mulheres migrantes no passado e no presente: gênero, redes sociais e migração internacional. Revista Estudos Feministas, v. 15, n. 3, p. 30-47, 2007.

BAENINGER, Rosana; VEDORATO, Luis Renato; NANDY, Sailen (Coords.). VON ZUBEN, Catarina; MAGALHÃES, Luis Felipe; PARISE, Paolo; DEMÉTRIO, Natália; DOMENICONI, Joice (Orgs.). Migrações internacionais e a pandemia de Covid-19. Campinas: Núcleo de estudos de população "Elza Berquó" (Nepo/Unicamp), 2020.

BERGALLO, Paola; MANGINI, Marcelo; MAGNELLI, Mariela; BERCOVICH, Sabina. The impacts of Covid-19 on women's economic autonomy in Latin America and the Caribbean. UNDP LAC C19 PDS, n. 25. Disponível em: <www.latinamerica.undp.org>. Acesso em: 10 Maio 2021. 
BOYD, Monica; GRIECO, Elizabeth. Women and migration: incorporating gender into international migration theory. Migration information source, 2003. Disponível em: <http://www.migrationinformation.org/Feature/display.cfm?id=106>. Acesso em: 21 Maio 2020.

CASTLES, Stephen; DE HAAS, Hein; MILLER, Mark J. The age of migration: international population movements in the modern world. London: Palgrave macmillan, 1998.

CAVALCANTI, Leonardo; OLIVEIRA, Antônio Tadeu; ARAUJO, Dina, A inserção dos imigrantes no mercado de trabalho brasileiro. Relatório Anual 2016. Observatório das Migrações Internacionais; Ministério do Trabalho/Conselho Nacional de Imigração e Coordenação Geral de Imigração. Brasília, OBMigra, 2016.

EHRENREICH, Barbara; HOCHSCHILD, Arlie. Introduction. In: EHRENREICH, B.; HOCHSCHILD, A. R. (Eds.). Global woman: nannies, maids and sex workers in the new economy, p. 1-13. New York: Metropolitan, 2002.

FOLEY, Laura; PIPER, Nicola. Covid-19 and women migrant workers: impacts and implications. In: IOM, UN migration, Covid-19 and the transformation of migration and mobility globally, 2020. Disponível em: <https://publications.iom.int/books/covid-19-and-women-migrant-workers-impacts-and-implications>. Acesso em: 15 Set. 2020.

HONDAGNEU-SOTELO, Pierrette. Gender and immigration: a retrospective and introduction. In: HONDAGNEU-SOTELO, P. (Ed.). Gender and US immigration: contemporary trends, p. 3-19. Berkeley, CA: University of California Press, 2003.

MASSEY, Douglas; ARANGO, Joaquín; GRAEME, Hugo; KOUAOUA, Ali; PELLEGRINO, Adela; TAYLOR, Edward. Theories of international migration: a review and appraisal. Population and Development Review, v. 19, n. 3, p. 431-66, 1993.

MAUSS, Marcel. Ensaio sobre a dádiva. In: Sociologia e antropologia. São Paulo: Cosac \& Naify, 2003.

MOROKVAŚIC, Mirjana. Birds of passage are also women. International Migration Review, v. 18, n. 4, p. 886-907, 1984.

MOTA, Camilla Veras. Covid-19 se alastra em frigoríficos e põe brasileiros e imigrantes em risco. BBC News Brasil, 22 Jul. 2020. Disponível em: <https://www.bbc.com/ portuguese/brasil-53477319>. Acesso em: 27 Dez. 2020.

PADILLA, Beatriz. A imigrante brasileira em Portugal: considerando o gênero na análise. In: MALHEIROS, J. (Ed.). Imigração brasileira em Portugal, p. 113-135. Lisboa: Observatório da imigração; Alto Comissariado para a Imigração e Diálogo Intercultural (Acidi), 2007. 
PARREÑAS, Rhacel. Inserting feminism in transnational migration studies. Migrationonline.cz, 2009. Disponível em: <http://www.migrationonline.cz/en/inserting-feminism-in-transnational-migration-studies>. Acesso em: 24 Jan. 2020.

The care crisis in the Philippines: children and transnational families in the new global economy. In: EHRENREICH, B.; HOCHSCHILD, A. R. (Eds.). Global woman: nannies, maids and sex workers in the new economy, p. 39-54. New York: Metropolitan, 2002.

Servants of globalization: women, migration and domestic work. Stanford, CA: Stanford University Press, 2001.

QUINTINO, Felipe; DICK, Paulo César; FURTADO, Ailton José; COSTA, Luiz Ferando. Notas Metodológicas. In: CAVALCANTI, Leonardo; OLIVEIRA, Tadeu; MACÊDO, Marília. Imigração e refúgio no Brasil. Relatório Anual 2020, p. 247 - 276. Série "Migrações". Observatório das Migrações Internacionais; Ministério da Justiça e Segurança Pública/ Conselho Nacional de Imigração e Coordenação Geral de Imigração Laboral. Brasília: OBMigra, 2020.

SAYAD, Abdelmalek . A imigração ou os paradoxos da alteridade. São Paulo: Editora USP, 2001.

SOUZA, Jeane; HEIDEMANN, Ivonete; PITILIN, Erica, BITENCOUR, Julia; VENDRUSCOLO, Carine; BRUM, Crhis. Determinantes sociais da saúde de mulheres imigrantes haitianas: repercussões no enfrentamento da Covid-19. Revista Eletrônica Enfermagem. v. 22, p. 1-8, 2020. Disponível em: <https://doi.org/10.5216/ree.v22.64362>. Acesso em: 9 Maio 2021.

TONHATI, Tânia. The transnational family: migration, family and rituals among Brazilian migrant women in the UK. Doctoral thesis, Goldsmiths, University of London, 2018. Disponível em: <http://research.gold.ac.uk/id/eprint/23046/>.

TONHATI, Tânia; MACÊDO, Marília. Imigração de mulheres no Brasil: movimentações, registros e inserção no mercado de trabalho formal (2010-2019). In: CAVALCANTI, Leonardo; OLIVEIRA, Tadeu; MACÊDO, Marília. Imigração e refúgio no Brasil Relatório Anual 2020, p. 111 - 141. Série "Migrações". Observatório das Migrações Internacionais; Ministério da Justiça e Segurança Pública/ Conselho Nacional de Imigração e Coordenação Geral de Imigração Laboral. Brasília: OBMigra, 2020.

UNITED NATIONS WOMEN. Policy brief: the impact of Covid-19 on women, 9 Abr. 2020. Disponível em: <https://www.unwomen.org/en/digital-library/publications/2020/04/policy-brief-the-impact-of-covid-19-on-women>. Acesso em: 10 Ago. 2020. 
UNITED NATIONS DEPARTMENT OF ECONOMIC AND SOCIAL AFFAIRS, POPULATION DIVISION. International migration 2019: Report (ST/ESA/SER.A/438), 2019.

WILGES, Leticia; SOARES, Sandra. Mulheres imigrantes venezuelanas no contexto da pandemia da Covid-19 na política de assistência social do município de Venâncio Aires, Rio Grande do Sul. Anais. Porto Alegre: Editora Pucrsbr, 2020. Disponível em: <https://editora.pucrs.br/edipucrs/acessolivre/anais/serpinf-senpinf/assets/ edicoes/2020/arquivos/125.pdf>. Acesso em: 9 Maio 2021.

ZLOTNIK, H. The global dimensions of female migration. Migration Policy Institute, 2003. Disponível em: <https://www.migrationpolicy.org/article/global-dimensionsfemale-migration>. Acesso em: 22 Dez. 2020. 